\title{
Extração, análise e distribuição dos ácidos fenólicos em genótipos pigmentados e não pigmentados de arroz (Oryza sativa L.)
}

\author{
Extraction, analysis and distribution of phenolic acids in pigmented \\ and non-pigmented genotypes of rice (Oryza sativa L.)
}

\author{
Nádia Valéria Mussi de MIRA ${ }^{1}$, Rosa Maria Cerdeira BARROS ${ }^{1}$, Moacir Antonio SCHIOCCHET², \\ José Alberto NOLDIN², Ursula Maria LANFER-MARQUEZ ${ }^{1 *}$
}

\section{Resumo}

Neste estudo, avaliaram-se a distribuição dos Compostos Fenólicos Totais (CFT) e o perfil de ácidos fenólicos, presentes nas frações, solúvel e insolúvel de dez genótipos de arroz (Oryza sativa L.) de pericarpo pigmentado e não pigmentado. Devido à sua elevada capacidade antioxidante, os compostos fenólicos vem sendo apontados como possíveis promotores da saúde. Grande parte corresponde aos ácidos fenólicos presentes no grão sob a forma solúvel (livre e conjugada) e insolúvel (ligada). Na literatura há poucas informações sobre a contribuição dos compostos fenólicos ligados, cujos teores são costumeiramente subestimados. Os CFT foram quantificados pelo método de Folin-Ciocalteau, enquanto os ácidos fenólicos por RP-HPLC. Na fração solúvel dos genótipos pigmentados, os teores de CFT foram variáveis, mas, em média, 5,7 vezes maiores do que nos não pigmentados (média de 3468 e $602 \mu \mathrm{g}$ eq. Ácido Ferúlico (AF)/g arroz, respectivamente), principalmente devido à presença de antocianinas e proantocianidinas. Na fração insolúvel, os pigmentados apresentaram duas vezes mais CFT do que os não pigmentados (825 e $378 \mu \mathrm{g}$ eq. AF/g arroz, respectivamente), provavelmente devido à retenção de antocianinas e proantocianidinas, mesmo após cinco extrações consecutivas. Dentre os ácidos fenólicos, o ácido ferúlico foi o principal componente em todos os genótipos estudados, exceto no arroz preto, no qual predominou o ácido protocatecóico.

Palavras-chave: arroz; Oryza sativa; cultivares; compostos fenólicos; ácido ferúlico; ácidos hidroxicinâmicos.

\begin{abstract}
This study was conducted to evaluate the distribution of total phenolic compounds and phenolic acids in the soluble and insoluble fractions of 10 rice (Oryza sativa L.) genotypes with pigmented or non-pigmented pericarp. These compounds were reported to exert beneficial effects on human health due to their high antioxidant activities. The total phenolic compounds (CFT) in both fractions was determined by the Folin-Ciocalteau method and phenolic acids RP-HPLC with Diode-Array Detection (DAD) in order to analyze phenolic acids. The amount of CFT in the soluble fraction was about 5.7 times higher in pigmented than in non-pigmented genotypes showing mean values of 3468 and $602 \mu \mathrm{g}$ eq.ferulic acid/g rice, respectively. The presence of proanthocyanidins and anthocianins seems to be responsible for the higher amounts. The average amounts of CFT in the insoluble fraction was two-fold higher in the pigmented than in the non pigmented genotypes ( 825 e $378 \mu \mathrm{g}$ eq. ferulic acid/g rice, respectively) probably due to the retention of antocyanidins and proanthocyanidins even after five consecutive extractions. Among the phenolic acids, the ferulic acid was the major phenolic acid found among all genotypes analyzed, except for the black pericarp in which the protocatechuic acid was predominant.

Keywords: rice; Oryza sativa; cultivars; phenolic compounds; hydroxycynnamic acids; ferulic acid.
\end{abstract}

\section{Introdução}

Cereais integrais têm um papel importante na nutrição humana. Dentre estes, o arroz, importante commodity agrícola que representa um quarto da produção mundial de grãos é responsável por $20 \%$ do suprimento calórico da dieta, enquanto o trigo e o milho provêem 19 e 5\%, respectivamente (FAO, 2004).

A Organização das Nações Unidas para Agricultura e Alimentação (FAO, 2004) calcula que o arroz é consumido por cerca de três bilhões de pessoas, correspondendo à metade da população mundial e, segundo estimativas oficiais no Brasil, até 2050 haverá uma demanda para atender ao dobro desta população (BRASIL, 2007; EMBRAPA, 2006).

Estudos epidemiológicos sugerem que a ingestão regular de grãos integrais reduz o risco de doenças crônicas associadas a danos oxidativos, como doenças cardiovasculares, câncer e outras patologias (SLAVIN, 2004; ARTS; HOLLMAN, 2005). Em vista da contínua promoção dos benefícios funcionais e de saúde, o consumo de arroz integral vem sendo estimulado por 
meio de propagandas e campanhas que o recomendam como parte de uma dieta saudável (HEINEMANN et al., 2005).

Embora o arroz seja consumido principalmente na forma polida, o arroz integral vem sendo considerado excelente fonte de energia, nutrientes, fibras e compostos bioativos. A demanda por arroz tem apresentado um incremento anual da ordem de $4 \%$, parcialmente devido ao seu emprego como ingrediente em novas formulações, tais como cereais matinais, barras de cereais, pães e massas (PSZCZOLA, 2001). Pesquisas indicam que o arroz, além do $\gamma$-orizanol e homólogos da vitamina $\mathrm{E}$, contém uma gama de compostos fenólicos, que complementam aqueles consumidos através de frutas e vegetais (GOFFMAN; BERGMAN, 2002).

Os compostos fenólicos do arroz incluem derivados de ácidos benzóicos e hidroxicinâmicos, principalmente o ácido ferúlico e diferulatos, e nos genótipos pigmentados ainda são encontrados antocianinas e proantocianidinas. Todas estas substâncias têm recebido atenção pelos seus potenciais efeitos biológicos benéficos para a saúde humana. A literatura reporta atividade antioxidante, antiinflamatória, antimutagênica e anticarcinogênica, além de sua habilidade para modular algumas atividades enzimáticas no interior da célula (MAILLARD; BERSET, 1995; LLOYD, SIEBENMORGEN; BEERS, 2000; LIU, 2004; PRIOR, WU; SCHAICH, 2005; CHUN et al., 2005; SOOBRATTEE et al., 2005).

A atividade biológica dos compostos fenólicos depende primariamente da sua absorção e metabolização, que, por sua vez, está relacionada com a estrutura química, conjugação com outras substâncias, grau de polimerização e solubilidade. Portanto, a grande diversidade estrutural dos compostos fenólicos dificulta enormemente o estudo da biodisponibilidade e dos efeitos fisiológicos, tendo motivado uma classificação em compostos fenólicos solúveis e insolúveis.

Os compostos fenólicos solúveis encontram-se compartimentalizados dentro dos vacúolos celulares (BECKMAN, 2000), e estão na forma livre ou conjugada, enquanto os fenólicos insolúveis encontram-se ligados a estruturas da parede celular, esterificados com arabinose ou resíduos de galactose dos componentes pécticos ou hemicelulósicos (FAULDS; WILLIAMSON, 1999). Os ácidos fenólicos livres representam a menor parte dos compostos fenólicos e são solúveis em soluções aquosas-orgânicas, tais como metanol, etanol ou acetona (TIAN, NAKAMURA; KAYAHARA, 2004). Os compostos fenólicos conjugados freqüentemente estão sob a forma de ésteres e amidas, raramente ocorrendo como glicosídeos. Eles incluem compostos de baixo peso molecular, solúveis em água, presentes no citosol, ou formas lipossolúveis, associadas às ceras da superfície da planta (KARAKAYA, 2004).

Estudos têm demonstrado que os ácidos ferúlico e cumárico podem ser liberados da matriz devido à natureza lábil da ligação éster no meio alcalino do intestino delgado e também pela ação das bactérias fermentativas no íleo terminal (BUCHANAN, WALLACE; FRY, 1996; BRAVO, 1998). Este fato abre a possibilidade dos compostos fenólicos insolúveis serem absorvidos, ao menos parcialmente.
Adom e Liu (2002) descreveram que os compostos fenólicos ligados contribuem com uma porção importante dos fenólicos totais em grãos, embora os seus teores pareçam ser rotineiramente subestimados em grãos como milho, aveia, trigo e arroz devido aos métodos insatisfatórios para a sua extração. Logo, sua contribuição na atividade antioxidante e biológica em geral parece estar subestimada (GOFFMAN; BERGMAN, 2004; PÉREZ-JIMÉNEZ; SAURA-CALIXTO, 2005; KIM et al., 2006).

A solubilidade dos compostos fenólicos é governada pela polaridade do solvente utilizado, seu grau de polimerização, sua interação com outros constituintes do alimento e formação de complexos insolúveis. Assim, fatores como composição do solvente, tempo e temperatura de extração, relação solvente:amostra, tratamento da amostra, entre outros, têm influência significativa na eficácia de extração, refletindo na maior ou menor recuperação dos compostos fenólicos (WU et al., 2004; LIYANA-PATHIRANA; SHAHIDI, 2005; NAM et al., 2005; SU et al., 2007).

Com relação à extração de compostos fenólicos ligados, os dados na literatura são escassos para arroz, mas, para cereais como o trigo, a extração por hidrólise alcalina tem sido recomendada desde que cuidados com tempo e temperatura de extração sejam observados; caso contrário pode ocorrer perda de até 50\% dos compostos fenólicos (YEN; HUNG, 2000; ADOM; LIU, 2002; NACZK; SHAHIDI, 2004).

Esses dados fortaleceram o nosso interesse no estudo da distribuição dos compostos fenólicos nas formas livre, conjugada e ligada em genótipos de arroz com pericarpo pigmentado e não pigmentado.

\section{Material e métodos}

\subsection{Reagentes}

Padrões dos ácidos, ferúlico, $\rho$-cumárico, vanílico e protocatecóico foram adquiridos da Sigma-Aldrich Co. Metanol e acetonitrila, de grau HPLC foram usados nas análises dos ácidos fenólicos. Os demais reagentes foram grau p.a.

\subsection{Amostras de arroz}

Foram avaliadas amostras de 10 genótipos de arroz (Oryza sativa, L.), sendo cinco de cultivares não pigmentados (SCSBRS Tio Taka; SCS 112; SCS 115 CL; Epagri 109) e cinco pigmentados, sendo quatro com pericarpo avermelhado (arroz-vermelho; ITJ 80; ITJ 75 e ITJ 31) e um genótipo com pericarpo preto (arroz-preto). Todas as amostras pertenciam à subespécie indica, exceto o arroz preto, que pertencia à subespécie japônica. As amostras foram obtidas de grãos produzidos na safra 2006/07 da Epagri/Estação Experimental de Itajaí, SC, localizada na latitude $26^{\circ} 57^{\prime} 57^{\prime \prime} \mathrm{S}$, longitude $48^{\circ} 48^{\prime} 01^{\prime \prime} \mathrm{W}$ e altitude $2 \mathrm{~m}$. Os grãos foram descascados para obtenção do arroz integral.

As amostras foram moídas em moinho analítico (Analytical Mill A10, Kinematica AG, Luzern, Suíça), tamisadas em peneira com abertura de 20 mesh e acondicionadas em frascos herméticos à temperatura ambiente até o momento das análises. 


\subsection{Métodos}

\section{Extração dos compostos fenólicos}

A extração e fracionamento dos compostos fenólicos estão descritos a seguir, tendo sido adaptados a partir de diversos procedimentos reportados na literatura (ADOM; LIU, 2002; TIAN, NAKAMURA; KAYAHARA, 2004; ZHOU et al., 2004; GALLARDO, JIMÉNEZ; GARCÍA-CONESA, 2006; LIYANA-PATHIRANA; SHAHIDI, 2006). A umidade das amostras foi determinada de acordo com método descrito pela AOAC (1995), sendo os resultados expressos em base seca (b.s.).

a) Extração dos Compostos Fenólicos Solúveis (CFS): dois g de farinha de arroz foram extraídos com $10 \mathrm{~mL}$ de etanol $80 \%$ por 10 minutos. Após centrifugação a $5000 \times$ x por 10 minutos, o sobrenadante foi coletado em balão volumétrico de $25 \mathrm{~mL}$ e o resíduo submetido a duas reextrações, uma com 10 e outra com $5 \mathrm{~mL}$ de etanol 80\%. Os sobrenadantes foram combinados e o volume completado para $25 \mathrm{~mL}$ com etanol $80 \%$. Todas as extrações foram realizadas em triplicata e os extratos estocados a $-40^{\circ} \mathrm{C}$ até o momento da análise; e

b) Extração dos Compostos Fenólicos Insolúveis (CFI): o resíduo obtido na etapa anterior foi desengordurado com $10 \mathrm{~mL}$ de hexano para eliminar compostos lipossolúveis que poderiam interferir nessa etapa. Após centrifugação a $7000 \times$ g por 10 minutos, desprezou-se o sobrenadante. $\mathrm{O}$ resíduo foi submetido à hidrólise alcalina por 4 horas à temperatura ambiente pela adição de $60 \mathrm{~mL}$ de $\mathrm{NaOH}$ $4 \mathrm{M}$ em frasco tampado sob atmosfera de $\mathrm{N}_{2}$ para evitar a oxidação dos compostos. Após esse período, a mistura foi resfriada em banho de gelo e adicionada de aproximadamente $20 \mathrm{~mL}$ de $\mathrm{HCl}$ concentrado até $\mathrm{pH}$ em torno de 1,5 e centrifugada a $7000 \times$ g por 30 minutos. O sobrenadante foi extraído com 5 porções de $30 \mathrm{~mL}$ cada de acetato de etila, sendo a fração orgânica recolhida e evaporada em evaporador rotatório até secura. O resíduo contendo os compostos fenólicos insolúveis foi ressuspenso em $10 \mathrm{~mL}$ de etanol $80 \%$ e estocado a $-40{ }^{\circ} \mathrm{C}$ até o momento da análise.

\section{Análise dos compostos fenólicos totais (CFT)}

Empregou-se a metodologia descrita por Singleton et al. (1999), com pequena modificação, neutralizando a solução com $\mathrm{NaOH} 0,5 \mathrm{M}$ ao invés de $\mathrm{Na}_{2} \mathrm{CO}_{3}$. Diluições apropriadas de cada extrato foram oxidadas pelo reagente de Folin-Ciocalteau e posteriormente neutralizadas. Após duas horas, a absorbância foi medida em espectrofotômetro em $760 \mathrm{~nm}$. Utilizou-se o ácido ferúlico como padrão, sendo os teores de Compostos Fenólicos Totais (CFT) expressos em equivalentes de ácido ferúlico por grama de arroz em base seca ( $\mu$ g eq.AF/g). Foi construída uma curva padrão de seis pontos variando a concentração do ácido ferúlico entre 25 e $100 \mu \mathrm{g}$. Os resultados das análises realizadas em triplicata foram reportados como média e desvio padrão.

\section{Extração dos ácidos fenólicos}

A extração dos ácidos fenólicos das frações solúvel e insolúvel de cada amostra de arroz seguiu o protocolo descrito na Figura 1, obtendo-se três extratos: de ácidos fenólicos livres (AFL), conjugados (AFC) e insolúveis (AFI).

\section{Separação e identificação dos ácidos fenólicos por HPLC}

Foi utilizado um cromatógrafo (Shimadzu, Tokyo, Japan, CLASS-M10A), equipado com três bombas LC-10ADP, injetor automático (SIL-10ADVP), forno com controle de temperatura (CTO-10ASVP), detector de arranjos de fotodiodos (SPD-M10AVP) e um sistema de software (Class VP 5.032) para a aquisição de dados. Para a separação dos ácidos fenólicos, foi utilizada coluna de fase reversa C18 VYDAC (4,6 x $250 \mathrm{~mm}$, $5 \mu \mathrm{m})$ e um sistema de solventes constituído pelas fases móveis: (A) água acidificada com $0,025 \%$ ácido trifluoracético (TFA) e (B) acetonitrila grau HPLC. Estabeleceu-se o seguinte gradiente de eluição: 0 minuto, $5 \%$ solvente B; 5 minutos, $9 \%$ solvente $B$; 15 minutos $9 \%$ solvente $B$; 22 minutos, $11 \%$ solvente $B$; e 38 minutos, $18 \%$ solvente B. O tempo de lavagem foi de 8 minutos com $80 \%$ solvente $\mathrm{B}$ e o período de equilíbrio entre as corridas individuais foi de 15 minutos com $5 \%$ do solvente B. Os parâmetros foram adaptados de Sheng et al. (2005) e Tian et al. (2005). O volume de injeção foi de $20 \mu \mathrm{L}$, o fluxo de $0,8 \mathrm{~mL} /$ minutos e a temperatura da coluna foi mantida em $38^{\circ} \mathrm{C}$. O detector UV/ Vis foi monitorado a 280 e $325 \mathrm{~nm}$ e o espectro de absorção foi gravado na faixa de comprimento de onda de 200 a $600 \mathrm{~nm}$. Cada extrato foi injetado em triplicata genuína.

Os ácidos fenólicos foram identificados pela comparação dos tempos de retenção e espectros de absorção com diversos padrões de ácidos fenólicos apresentados na Figura 2 e por comparação com dados da literatura (BECKMAN, 2000). Foram construídas curvas padrão com sete pontos para os ácidos fenólicos predominantes no arroz: ferúlico, p-cumárico e protocatecóico na faixa de concentração 4,8 a $55 \mu \mathrm{g} \cdot \mathrm{mL}^{-1}$. Todas as análises foram realizadas em triplicata.

\section{Análise estatística}

Todas as análises foram executadas com base nas triplicatas das amostras e os dados foram expressos como média \pm desvio padrão. A análise estatística foi realizada usando o software Statistica (versão 7). A análise de variância foi conduzida (ANOVA), seguido do teste de Tukey para determinar as diferenças entre as médias dos grupos a um nível de significância $\mathrm{p}<0,05$.

\section{Resultados e discussão}

\subsection{Compostos fenólicos totais (CFT) nas frações solúvel e insolúvel}

Na Figura 3, é apresentada a distribuição dos teores de CFT nas frações solúvel e insolúvel dos genótipos de arroz não pigmentado e pigmentado. Os resultados foram expressos em $\mu \mathrm{g}$ equivalentes de ácido ferúlico por grama de arroz em base seca ( $\mu$ g eq $\mathrm{AF} / \mathrm{g})$. 
Mira et al.

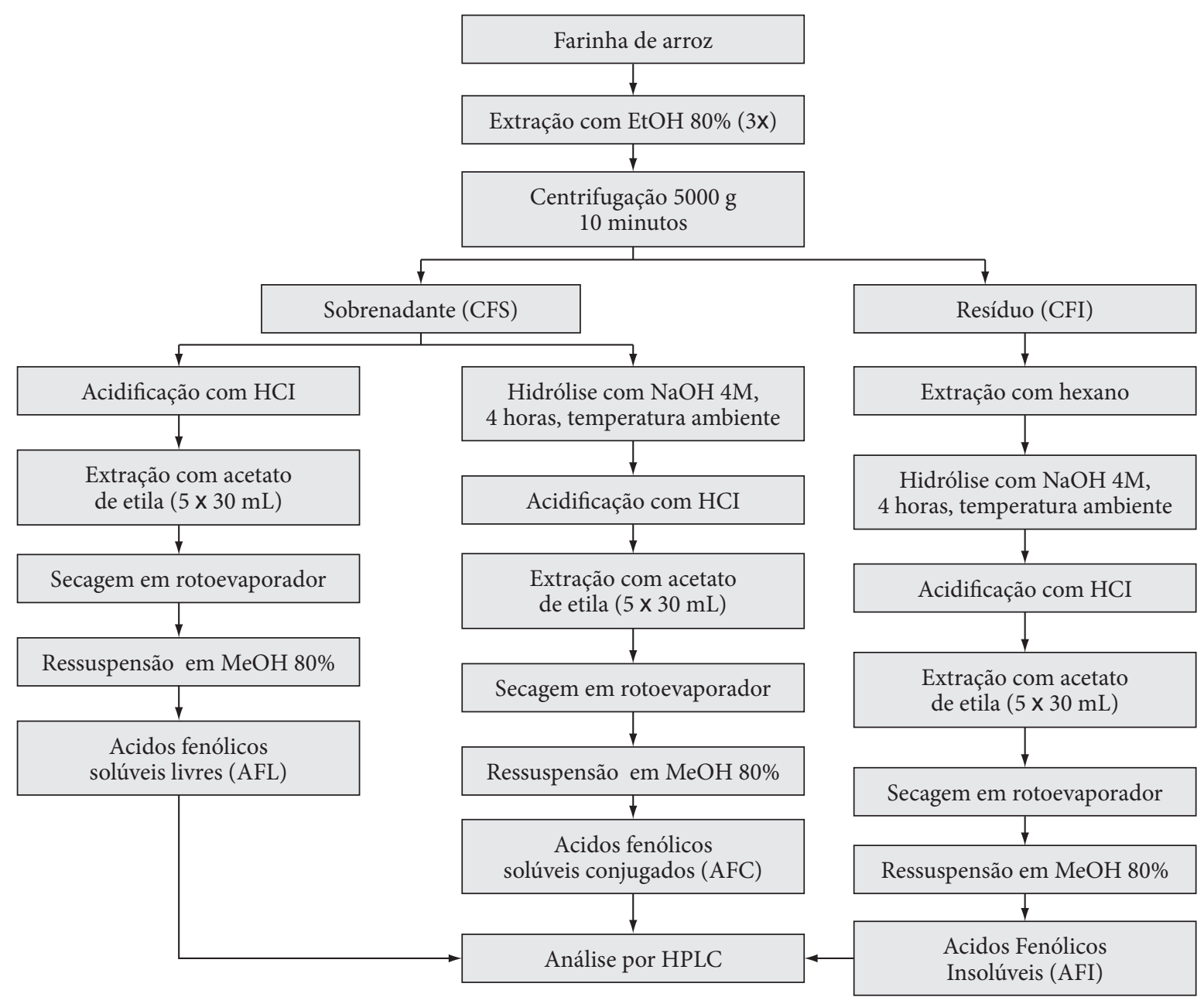

Figura 1. Fluxograma de extração dos ácidos fenólicos das frações solúvel e insolúvel.
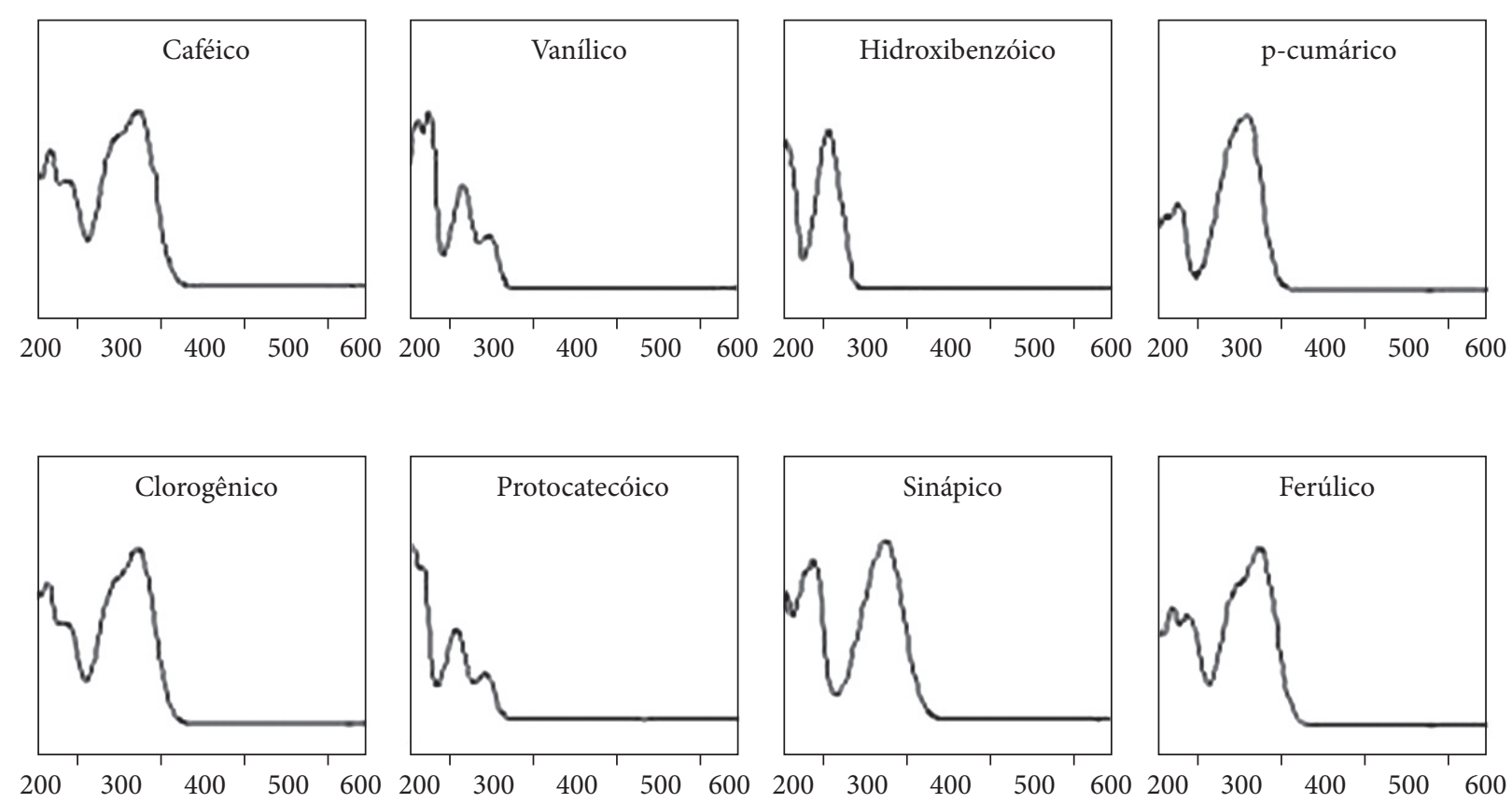

$\mathrm{nm}$

Figura 2. Espectros de absorção dos padrões de ácidos fenólicos (200-600 nm). 


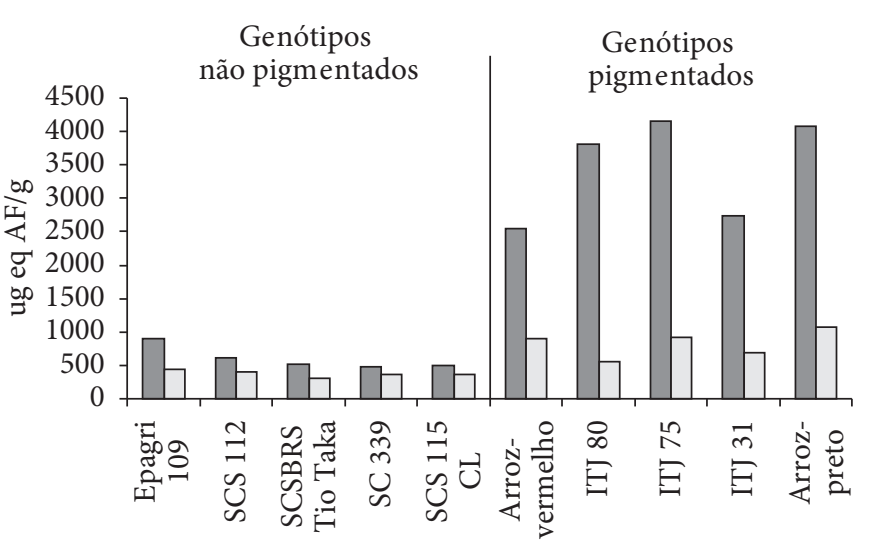

๑ Fração solúvel $\quad$ Fração insolúvel

Figura 3. Compostos Fenólicos Totais (CFT) nas frações solúvel e insolúvel de genótipos de arroz não pigmentado e pigmentado, expressos em $\mu$ g eq. Ácido Ferúlico (AF)/g arroz.

Os teores de CFT na fração solúvel nos cinco extratos de arroz não pigmentado variaram entre 480 e $902 \mu \mathrm{g}$ eq AF/g, com um valor médio de $602 \mu \mathrm{g}$ eq. AF/g. Os extratos de arroz com pericarpo pigmentado apresentaram teores entre 2556 e $4145 \mu \mathrm{g}$ eq. AF/g, e valor médio de $3468 \mu \mathrm{g}$ eq AF/g, teor este, 5,7 vezes superior ao do arroz não pigmentado. ADOM e LIU (2002), na análise de uma única amostra de arroz não pigmentado, reportaram na fração solúvel um teor de CFT de $357 \mathrm{mg}$ eq. ácido gálico/kg amostra. GOFFMAN e BERGMAN (2002), em amplo estudo de triagem com 320 amostras de arroz com diferentes graus de coloração, encontraram teores de CFT solúveis que variaram entre 290 e $5830 \mathrm{mg}$ eq. ácido gálico/ $\mathrm{kg}$, sendo que os cultivares pigmentados apresentaram valores próximos aos determinados neste trabalho quando recalculados para a mesma unidade.

Os elevados teores de CFT na fração solúvel dos genótipos pigmentados devem-se à presença de antocianidinas e proantocianidinas, responsáveis pela coloração dos grãos. No entanto, acredita-se que estes flavonóides intactos sejam pouco absorvidos pelo trato gastrointestinal, em função do seu elevado peso molecular, mas poderiam alcançar o cólon onde seriam metabolizados pela microflora intestinal. A atividade biológica dos metabólitos produzidos, que poderia ser exercida no próprio trato gastrointestinal (TGI), tem sido pouco estudada até o momento (SCALBERT et al., 2002). Assim, as proantocianidinas, que são polímeros de flavonóides com grau variável de polimerização, aparentemente contribuem pouco com a atividade biológica na fase pós-absortiva. Por outro lado, segundo SOOBRATTEE et al. (2005) dímeros de proantocianidinas e flavanóis mostraram atividade antioxidante potente. Na fração insolúvel, os valores de CFT para os genótipos não pigmentados e pigmentados foram em média, 378 e $825 \mu \mathrm{g}$ eq AF/g, respectivamente, apresentando uma variação individual pequena em cada um dos dois grupos de genótipos de arroz. As amostras pigmentadas apresentaram valores superiores às não pigmentadas e, neste caso, uma possível explicação poderia ser a retenção de antocianinas e proantocianidinas na matriz, uma vez que a fração apresentava coloração avermelhada mesmo após cinco extrações consecutivas. Os compostos fenólicos da fração insolúvel dos genótipos não pigmentados participam em média, com $39 \%$ do total dos compostos fenólicos presentes, indicando que esta fração representa uma parte importante da totalidade, fato que estimula pesquisas de caracterização química e de avaliação de sua eventual atividade biológica.

\subsection{Identificação dos ácidos fenólicos por HPLC}

Na Figura 4, são apresentados perfis cromatográficos típicos das frações solúvel e insolúvel de genótipos de arroz não pigmentado e pigmentado.

A fração solúvel de todos os genótipos não pigmentados apresentou um cromatograma complexo similar àquele apresentado na Figura 4a. A maior parte dos componentes não pôde ser identificada no primeiro momento, por tratar-se de compostos fenólicos conjugados, para os quais não há padrões comercialmente disponíveis. Após hidrólise alcalina desta fração, a maioria dos picos desapareceu, resultando em um perfil com apenas dois picos com áreas aumentadas, correspondentes aos ácidos ferúlico e p-cumárico (Figura $4 \mathrm{~b}$ ). Este resultado comprova que a fração solúvel é constituída principalmente por ésteres dos dois ácidos mencionados.

Da mesma forma, na Figura 4c, a fração insolúvel dos genótipos não pigmentados após hidrólise, evidenciou a presença exclusiva dos ácidos ferúlico e p-cumárico.

A composição da fração solúvel e insolúvel dos genótipos com pericarpo vermelho foram similares às observadas nos genótipos não pigmentados (Figura 4d-f), indicando também a presença de compostos conjugados derivados dos ácidos ferúlico e p-cumárico. Contudo, alguns genótipos além da predominância dos ácidos ferúlico e p-cumárico continham quantidades reduzidas de outros ácidos, conferindo um perfil particular para cada uma das amostras analisadas.

Entre os genótipos estudados, o arroz-preto apresentou perfil de ácidos fenólicos diferenciado. A fração solúvel (Figura 5a), embora rica em compostos conjugados, apresentou grande quantidade de ácido protocatecóico. Após hidrólise alcalina (Figura 5b), foram identificados os ácidos, protocatecóico, vanílico, p-cumárico e ferúlico. Ácidos estes também observados por CHUNG e SHIN (2007). A fração insolúvel (Figura 5c) mostrou predominância do ácido protocatecóico, seguida pelos ácidos ferúlico, vanílico e p-cumárico.

\subsection{Quantificação dos ácidos fenólicos}

Na Tabela 1, são apresentados os teores de ácidos ferúlico e p-cumárico em cada fração analisada, sendo os resultados expressos em $\mu$ g.g $\mathrm{g}^{-1}$ de arroz em base seca (b.s.). A soma dos ácidos fenólicos das frações solúvel e insolúvel nos genótipos não pigmentados foi em média $280 \mu \mathrm{g} \cdot \mathrm{g}^{-1}$, sendo que a fração insolúvel representou uma parte importante, contribuindo com cerca de $80 \%$ da totalidade dos ácidos. Já as frações, conjugada e livre, corresponderam a aproximadamente $16 \% 44(\mathrm{ug} / \mathrm{g})$ e a $3 \%$ (8 ug/g), respectivamente. Os ácidos fenólicos predominantes dessas amostras foram o ácido ferúlico com $78 \%$, seguido do 

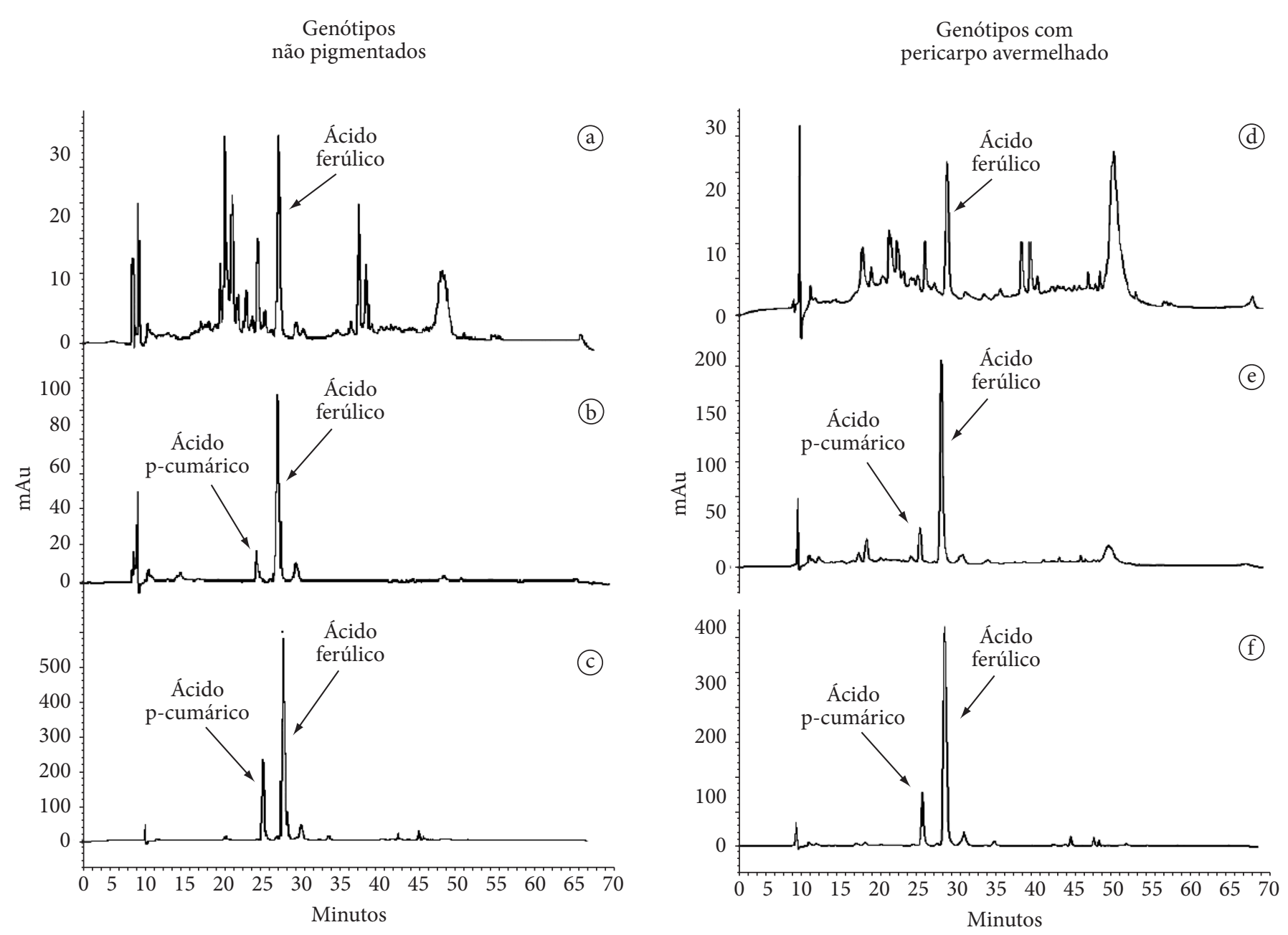

Figura 4. Cromatogramas típicos das frações solúvel e insolúvel de genótipos não pigmentados e pigmentados (pericarpo avermelhado): a, d) fração solúvel antes da hidrólise; b, e) depois da hidrólise; e c, f) fração insolúvel.

Tabela 1. Teores dos ácidos ferúlico e cumárico nas frações solúvel (livre e conjugada) e insolúvel, nos genótipos não pigmentados e pigmentados com pericarpo avermelhado.

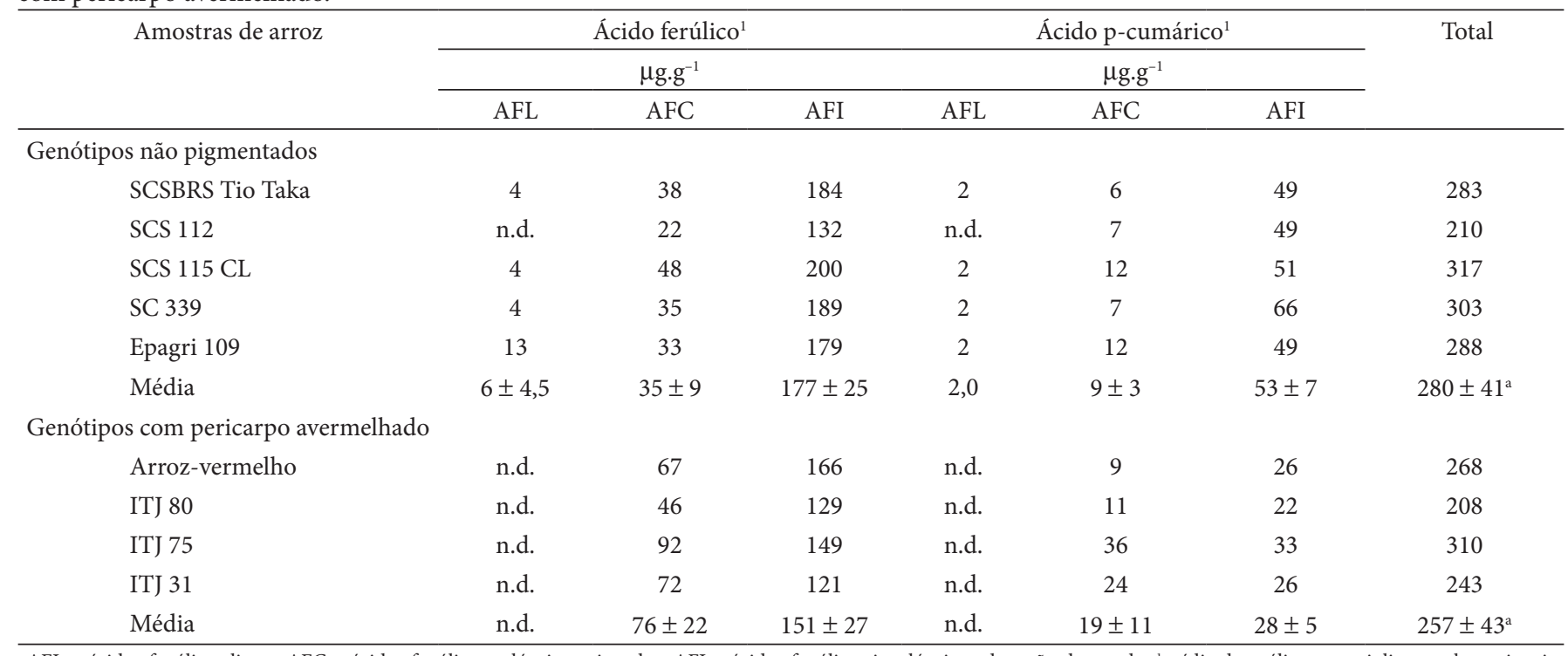

$\mathrm{AFL}$ = ácidos fenólicos livres; $\mathrm{AFC}$ = ácidos fenólicos solúveis conjugados; $\mathrm{AFI}=$ ácidos fenólicos insolúveis; n.d. = não detectado; ${ }^{1}$ média de análises em triplicata; e letras iguais indicam valores sem diferença significativa $(\mathrm{p}<0,05)$. 


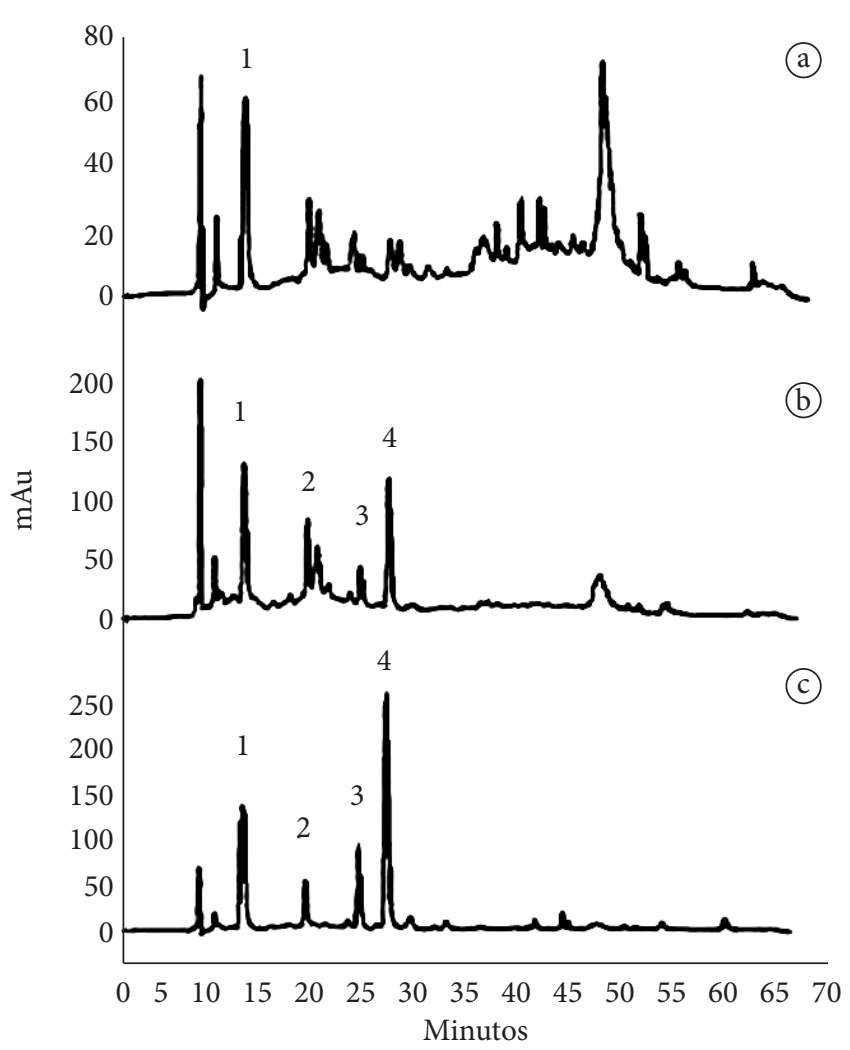

\begin{tabular}{|ll|}
\hline 1 - ácido protocatecóico & 3 - ácido p-cumárico \\
2 - ácido vanílico & 4 -ácido ferúlico
\end{tabular}

Figura 5. Cromatogramas das frações solúvel e insolúvel de uma amostra de arroz-preto: a) fração solúvel antes da hidrólise; b) depois da hidrólise; e c) fração insolúvel.

ácido p-cumárico com $22 \%$, similar à distribuição reportada por Adom e Liu (2002).

Com relação aos genótipos pigmentados com pericarpo avermelhado, a soma dos ácidos fenólicos das três frações foi em média de $257 \mu \mathrm{g} . \mathrm{g}^{-1}$, similar ao valor encontrado nos genótipos não pigmentados $(\mathrm{p}<0,05)$. A distribuição foi de $65 \%$ na fração insolúvel e de $34 \%$ na fração solúvel conjugada. Ácidos fenólicos na forma livre foram encontrados em quantidades muito reduzidas. Igualmente aos genótipos não pigmentados, os ácidos predominantes foram os ácidos ferúlico e p-cumárico.

$\mathrm{O}$ arroz-preto diferenciou-se dos demais genótipos na distribuição, composição e na totalidade dos ácidos fenólicos presentes. A soma dos ácidos fenólicos das três frações foi muito alta, perfazendo um total de $755 \mu \mathrm{g} . \mathrm{g}^{-1}$ de arroz. A distribuição foi em média de $70 \%$ na fração insolúvel e de $37 \%$ na fração solúvel, conjugada. Com relação à composição, o arroz-preto apresentou maior diversidade, com predominância do ácido protocatecóico (325 $\left.\mu \mathrm{g} \cdot \mathrm{g}^{-1}\right)$, seguido dos ácidos ferúlico, vanílico e p-cumárico (291, 89 e $50 \mu \mathrm{g} . \mathrm{g}^{-1}$, respectivamente). Com exceção do arroz-preto, o ácido ferúlico foi o ácido fenólico mais abundante em todos os genótipos estudados.
CHUNG e SHIN (2007) e YAWADIO et al. (2007) também identificaram os ácidos protocatecóico, vanílico e ferúlico como sendo os ácidos predominantes em uma amostra de arroz preto analisado por HPLC, acoplado à espectrometria de massas.

Os ácidos ferúlico e protocatecóico são considerados de alta atividade antioxidante in vitro, embora uma ordenação dos ácidos fenólicos por atividade seja difícil, pois ela pode variar em função do solvente, da concentração dos reagentes e do mecanismo de ação (SOOBRATTEE et al., 2005). Além disso, uma efetiva capacidade antioxidante em sistemas biológicos requer que esses compostos sejam absorvidos e distribuídos nos tecidos, o que levanta a problemática da sua biodisponibilidade sob a influência da matriz alimentar.

RONDINI et al. (2004) realizaram estudos in vivo para avaliar a biodisponibilidade do ácido ferúlico ligado (insolúvel) do farelo de trigo e concluíram que, embora a cinética de absorção entre o ácido ferúlico puro e aquele presente no farelo seja diferente, a rapidez na liberação no plasma é a mesma. Este resultado suporta a hipótese que os ácidos fenólicos ligados podem tornar-se biodisponíveis no trato gastrointestinal. Ademais, foi observado que o ácido ferúlico puro permanece no plasma por 4,5 horas, enquanto que o ácido ferúlico advindo do farelo é liberado mais lentamente pela ação de enzimas intestinais ou excretado pela bile e reabsorvido pelo intestino, permitindo que a concentração plasmática permaneça constante por um período maior, de 1 hora e meia a 24 horas.

É conhecido que os compostos fenólicos possuem considerável diversidade de estruturas químicas, pesos moleculares e diferentes solubilidades, fatores estes decisivos na sua biodisponibilidade. Os de menor peso molecular, em especial os ácidos fenólicos, parecem ser facilmente absorvidos no intestino delgado onde são conjugados para o-glicorunídeos, ésteres de sulfato e o-metiléter. A absorção tem sido demonstrada indiretamente pelo aumento da capacidade antioxidante do plasma (BOURNE; RICE-EVANS, 1998; ADAM et al., 2002; SCALBERT et al., 2002; TAPIERO et al., 2002; ZHAO, EGASHIRA; SANADA, 2003 e 2004).

Diante desse quadro, investigações sobre a biodisponibilidade do ácido ferúlico presente em arroz devem ser estimuladas, de modo a estabelecer seu verdadeiro potencial em proteger o organismo contra patologias envolvendo espécies reativas do oxigênio.

\section{Conclusões}

Os teores de compostos fenólicos solúveis (livres e conjugados) foram aproximadamente seis vezes superiores nos genótipos pigmentados devido à presença de proantocianidinas e antocianinas. Os compostos fenólicos insolúveis corresponderam em média a 39\% dos compostos fenólicos totais nos genótipos não pigmentados, indicando que esta fração contribui significativamente com a totalidade dos compostos fenólicos. Nos genótipos pigmentados, os compostos fenólicos insolúveis apresentaram aproximadamente o dobro de concentração, possivelmente devido à extração incompleta dos pigmentos vermelhos. Os teores dos ácidos ferúlico e p-cumárico foram similares para os diferentes genótipos estudados, exceto para 
o arroz-preto, no qual predominou o ácido protocatecóico. A concentração de ácidos fenólicos totais no arroz preto foi três vezes superior quando comparada ao valor médio encontrado nos genótipos não pigmentados e pigmentados com pericarpo avermelhado.

Os ácidos fenólicos são encontrados principalmente na fração insolúvel, o que sugere maiores estudos relativos à sua biodisponibilidade e atividade antioxidante, a fim de elucidar possíveis efeitos biológicos no organismo humano.

\section{Agradecimentos}

Ao CNPq pela concessão de bolsa PDJ Processo 154413/2006-2 e Auxílio à Pesquisa Processo 472473/2006-9.

\section{Referências bibliográficas}

ADAM, A. et al. The bioavailability of ferulic acid is governed primarily by the food matrix rather than its metabolism in intestine and liver rats. The journal of nutrition, v. 132, p. 1962-1968, 2002.

ADOM, K. K.; LIU, R. Antioxidant activity of grains. Journal of Agricultural and Food Chemistry, v. 50, n. 21, p. 6182-6187, 2002.

AOAC. Official Methods of Analysis of AOAC. $16^{\text {th }}$ ed. Arlington, VA, USA, 1995.

ARTS, I.; HOLLMAN, P. Polyphenols and disease risk in epidemiologic studies. The American Journal of Clinical Nutrition, v. 81, n. 1 supl, p. 317S-325S, 2005.

BECKMAN, C. H. Phenolic-storing cells: keys to programmed cell death and periderm formation in wilt disease resistance and in general defence responses in plants? Physiological and Molecular Plant Pathology, v. 57, n. 3, p. 101-110, 2000.

BOURNE, L. C.; RICE-EVANS, C. Bioavailability of ferulic acid. Biochemical and Biophysical Research Communications, v. 253, n. 3, p. 222-227, 1998.

BRASIL. Ministério da Agricultura, Pecuária e Abastecimento. Companhia Nacional de Abastecimento (Conab). Cenário Mundial Favorece Exportações Brasileira de Arroz. 2007. Disponível em: <www.conab.gov.br/conaweb>. Acesso em: 03 Agosto 2007.

BRAVO, L. Polyphenols: chemistry, dietary sources, metabolism, and nutritional significance. Nutrition reviews, v. 56, n. 11, p. 317-333, 1998.

BUCHANAN, C. J.; WALLACE, G.; FRY, S. C. In vivo release of ${ }^{14} \mathrm{C}-$ labeled phenolic groups from intact dietary spinach cell walls during passage through the rat intestine. Journal of the Science of Food and Agriculture, v. 71, p. 459-469, 1996.

CHUN, O. K. et.al. Daily consumption of phenolics and total antioxidant capacity from fruit and vegetables in the American diet. Journal of the Science of Food and Agriculture, v. 85, n. 10, p. 1715-1724, 2005.

CHUNG, H. S.; SHIN, J. C. Characterization of antioxidant alkaloids and phenolic acids from anthocyanin-pigmented rice (Oryza sativa cv. Heugjinjubyeo). Food Chemistry, v. 104, n. 4, p. 1670-1677, 2007.

EMBRAPA. Cultivo do Arroz Irrigado no Brasil. Importância Econômica, Agrícola e Alimentar do Arroz, 2006. Disponível em: $<$ http://sistemasdeproducao.cnptia. embrapa.br/FontesHTML/ Arroz/ArrozIrrigadoBrasil/Cap01.htm>. Acesso em: 17 Março 2006.
FAO. Agriculture. Featured Sites: Intenational Year of rice 2004. Fact Sheets. Rice and Human Nutrition, 2004. Disponível em: <www. fao.org/rice2004/en/factsheets.htm>. Acesso em: 20 Fevereiro 2006.

FAULDS, C. B.; WILLIAMSON, G. The role of hydroxycinnamates in the plant cell wall). Journal of the Science of Food and Agriculture, v. 79, n. 3, p. 393-395, 1999.

GALLARDO, C.; JIMÉNEZ, L.; GARCÍA-CONESA, M. T. Hydroxycinnamic acid composition and in vitro antioxidant activity of selected grain fractions. Food Chemistry, v. 99, n. 3, p. $455-463,2006$.

GOFFMAN, F. D.; BERGMAN, C. J. Total phenolics and radical efficiency of rice bran extracts. In: RICE TECHNICAL WORKSHOP GROUP MEET, 29, 2002, Little Rock, AR. Proceedings...

Rice kernel phenolic content and its relationship with antiradical efficiency. Journal of the Science of Food and Agriculture, v. 84, n. 10, p. 1235-1240, 2004.

HEINEMANN, R. J. B. et al. Comparative study of nutrient composition of commercial brown, parboiled and milled rice from Brazil. Journal of Food Composition and Analysis, v. 18, n. 4, p. 287-296, 2005.

KARAKAYA, S. Bioavailability of phenolic compounds. Critical Reviews in Food Science and Nutrition, v. 44, n. 6, p. 453-464, 2004.

KIM, H. K. et al. Phenolic acid profiles and antioxidant activities of wheat bran extracts and effect of hydrolysis conditions. Food Chemistry, v. 95, n. 3, p. 466-473, 2006.

LIU, R. H. Potencial synergy of phytochemicals in câncer prevention: mechanism of action. The American Society for Nutritional Sciences, v. 134, p. 3479S-3485S, 2004.

LIYANA-PATHIRANA, C.; SHAHIDI, F. Optimization of extraction of phenolic compounds from wheat using response surface methodoly. Food Chemistry, v. 93, n. 1, p. 43-56, 2005.

Importance of insoluble-bound phenolics to antioxidant properties of wheat. Journal of Agricultural and Food Chemistry, v. 54, n. 4, p. 1256-1264, 2006.

LLOYD, B. J.; SIEBENMORGEN, T. J.; BEERS, K. W. Effect of commercial processing on antioxidants in rice bran. Cereal Chemistry, v. 77, n. 5, p. 551-555, 2000.

MAILLARD, M. N.; BERSET, C. Evolution of antioxidant activity during kilning: Role of insoluble bound phenolic acids of barley and malt. Journal of Agricultural and Food Chemistry, v. 43, n. 7, p. 1789-1793, 1995.

NACZK, M.; SHAHIDI, F. Extraction and analysis of phenolics in food. Journal of Chromatography A, v. 1054, n. 1-2, p. 95-111, 2004.

NAM, S. H. et al. Antioxidative, antimutagenic and anticarcinogenic activies of rice bran extracts in chemical and cell assays. Journal of Agricultural and Food Chemistry, v. 53, n. 3, p. 816-822, 2005.

PÉREZ-JIMÉNEZ, J.; SAURA-CALIXTO, F. Literature data may underestimate the actual antioxidant capacity of cereals. Journal of Agricultural and Food Chemistry, v. 53, n. 12, p. 5036-5040, 2005.

PRIOR, R. L.; WU, X.; SCHAICH, K. Standardized methods for the determination of antioxidant capacity and phenolics in foods and dietary supplements. Journal of Agricultural and Food Chemistry, v. 53, n. 10, p. 4290-4302, 2005.

PSZCZOLA, D. E. Rice: not just for throwing. Food Technology, v. 55, n. 2, p. 53-59, 2001. 
RONDINI, L. et al. Bound ferulic acid from bran is more bioavailable than the free compound in rat. Journal of Agricultural and Food Chemistry, v. 52, n. 13, p. 4338-4343, 2004.

SCALBERT, A. et al. Absorption and metabolism of polyphenols in the gut and impact on health. Biomed Pharmacother, v. 56, p. 276-282, 2002.

SHENG, X. Y. et al. Simultaneous determination of galic acid, albiflorin, paenoniflorin, ferulic acid and benzoic acid in Si-Wu decoction by high-performance liquid chromatographic DAD method. Journal of Pharmaceutical and Biomedical Analysis, v. 37, p. 805-810, 2005.

SINGLETON, V. L.; ORTHOFER, R.; LAMMELA-RANVENSON, R. M. Analysis of total phenols and other oxidation substrates and antioxidants by means of Folin-Ciocalteau reagent. Methods of Enzymology, v. 299, p. 152-178, 1999.

SLAVIN, J. Whole grains and human health. Nutrition Research Reviews, v. 17, p. 99-110, 2004.

SOOBRATTEE, M. A. et al. Phenolics as potential antioxidant therapeutic agents: Mechanism and actions. Mutation research. Fundamental and Molecular Mechanisms of Mutagenesis, v. 579, n. 1-2, p. 200-213, 2005

SU, L. et al. Total phenolic contents, chelating capacities, and radicalscavenging properties of black peppercorn, nutmeg, rosehip, cinnamon and oregano leaf. Food Chemistry, v. 100, n. 3, p. 990-997, 2007.

TAPIERO, H. et al. Polyphenols: do they play a role in the prevention of human pathologies? Biomedicine and Pharmacotherapy, v. 56, n. 4 , p. $200-207,2002$.
TIAN, S.; NAKAMURA, K.; KAYAHARA, H. Analysis of phenolic compounds in white rice, brown rice and germinated brown rice. Journal of Agricultural and Food Chemistry, v. 52, n. 15, p. $4808-4813,2004$.

TIAN, S. et al. High-performance liquid chromatographic determination of phenolic compounds in rice. Journal of Chromatography A, v. 1063, n. 1-2, p. 121-128, 2005.

WU, X. et al. Development of a database for total antioxidant capacity in foods: a preliminary study. Journal of Food Composition and Analysis, v. 17, p. 407-422, 2004.

YAWADIO, R.; TANIMORI, S.; MORITA, N. Identification of phenolic compounds isolated from pigmented rices and their aldose reductase inhibitory activities. Food Chemistry, v. 101, n. 4, p. 161-1625, 2007.

YEN, G. C.; HUNG, C. Y. Effects of alkaline and heat treatment on antioxidative activity and total phenolics of extracts from Hsian-tsao. Food Research International, v. 33, n. 6, p. 487-492, 2000.

ZHAO, Z.; EGASHIRA, Y.; SANADA, H. Ferulic acid sugar esters are recovered in rat plasma and urine mainly as the sulfoglucuronide of ferulic acid. The Journal of nutrition, v. 133, n. 5, p. 1355-1361, 2003.

. Ferulic acid is quickly absorved from rat stomach as the free form and then conjugated mainly in liver. The American Society for Nutritional Sciences, v. 134, p. 3083-3088, 2004.

ZHOU, Z. et al. The distribution of phenolic acids in rice. Food Chemistry, v. 87, n. 3, p. 401-406, 2004. 